\title{
Vascularised fibula osteocutaneous flap for cervical spinal and posterior pharyngeal wall reconstruction
}

\author{
Krishnakumar Thankappan, Sandip Duarah, Nirav P. Trivedi, Dilip Panikar ${ }^{1}$, \\ Moni Abraham Kuriakose, Subramania lyer \\ Department of Head and Neck Surgery, ${ }^{1}$ Neurosurgery, Amrita Institute of Medical Sciences, Elamakkara, Kochi, India
}

Address for correspondence: Dr. Subramania lyer, Consultant, Head and Neck Institute and Chief, Division of Plastic and Reconstructive Surgery, Amrita Institute of Medical Sciences, Elamakkara, Kochi - 682 026, India. E-mail: subu@aims.amrita.edu

\section{ABSTRACT}

We report a case of vascularised fibula osteocutaneous flap used for composite cervical spinal and posterior pharyngeal wall reconstruction, in a patient with recurrent skull base chordoma, resected by an anterior approach via median labio-mandibular glossotomy approach. Bone stability and pharyngeal wall integrity were simultaneously restored

\section{KEY WORDS}

Free fibula flap; head and neck reconstruction; cervical spinal reconstruction; skull base chordoma; mandibulotomy approach

\section{INTRODUCTION}

icrovascular transfer of fibular bone has been used in many ways in reconstructive surgery. A case of skull base chordoma, which recurred multiple times, was resected by an anterior approach via median labio-mandibular glossotomy approach. Vascularised fibula osteocutaneous flap was used for cervical spinal and posterior pharyngeal wall reconstruction. The case demonstrates the complexity in the management of recurrent skull base chordomas, and the aptness of the flap in simultaneously restoring the bone stability and pharyngeal wall integrity.

\section{CASE REPORT}

A 41-year-old male with a history of chordoma of the cranio-vertebral junction operated upon multiple times earlier, presented with complaints of pain, limitation of neck movements, and difficulty in swallowing. The first surgery was done eight years back through a posterior approach, at which time the tumour was decompressed and an occipito-cervical stabilization was done. This was followed by transoral decompressions done on two occasions. Neurological examination revealed exaggerated deep tendon reflexes and extensor plantar reflex on the right side with intact cranial nerve functions, normal muscle bulk and power in all four limbs. A computed tomography (CT) scan showed a large recurrence [Figures 1 and 2] involving second and third cervical vertebral bodies, anterior arch and right lateral mass of atlas, right occipital condyle, anterior lip of foramen magnum and lower half of clivus. Right internal carotid artery was displaced anterolaterally and right vertebral artery was encased and pinched off by the tumour. Sub-arachnoid space C1-C3 was totally effaced, and significant secondary narrowing of the spinal canal was present.

After necessary preoperative evaluation and counselling he underwent a sub total excision of the tumour by median labio-mandibular glossotomy approach. 
Reconstruction was carried out using a vascularised fibula osteocutaneous flap. The fibular strut was used to reconstruct the vertebral column. It was wedged between healthy bone of the lower clivus and the $\mathrm{C} 3$ vertebral body, and held in place with a small mini-plate at the lower end of the graft. The skin paddle was used to reconstruct the posterior pharyngeal wall which was largely scarred from the previous surgeries and was excised with the tumour. The artery was anastomosed to the lingual artery and the

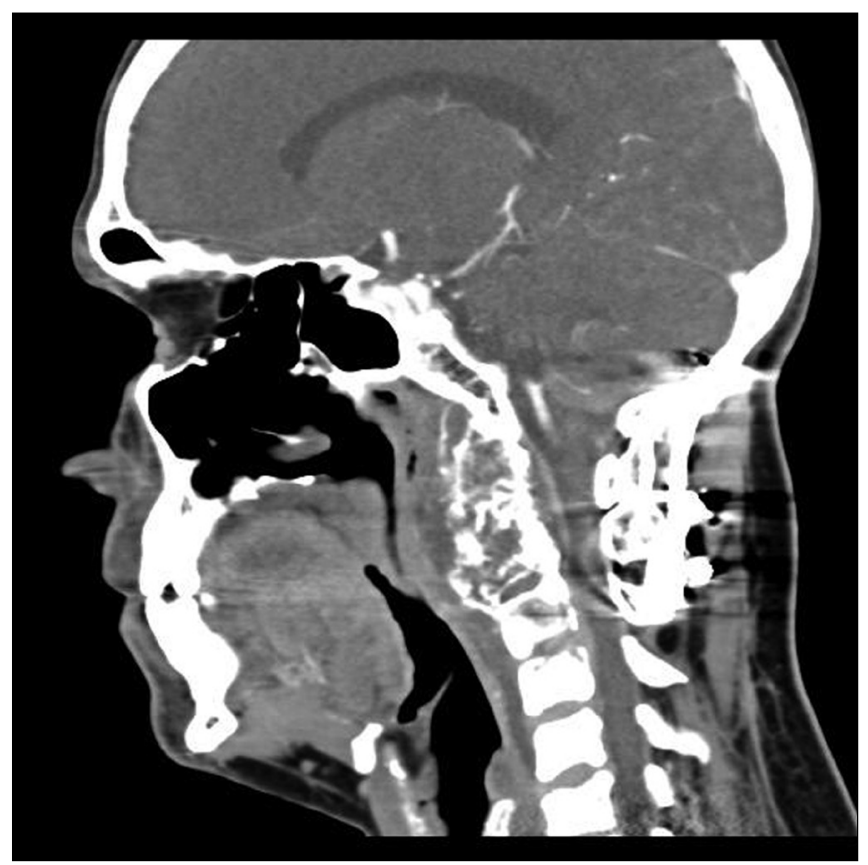

Figure 1: CT Scan (sagital view) showing the lesion

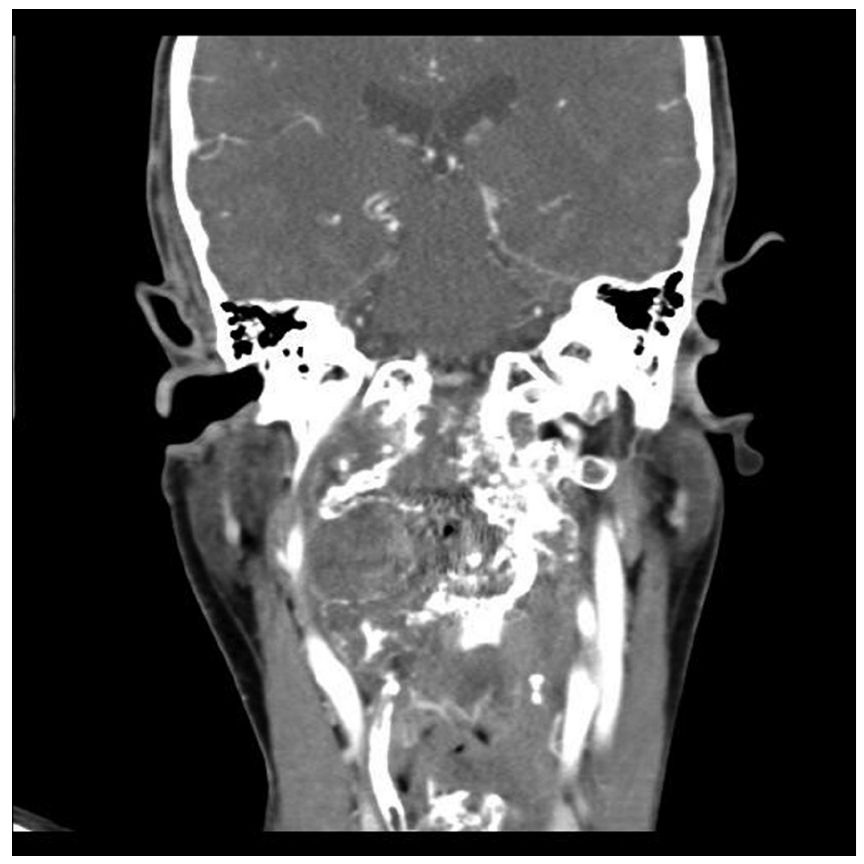

Figure 2: CT Scan (coronal view) showing the lesion vein to one of the tributaries of internal jugular vein in the neck. The recipient vessels in the neck were in close proximity to the donor vessels and so the length of the vascular pedicle was adequate. Figure 3 shows the threedimensional CT image after surgery. The skin paddle was periodically monitored directly in the oropharynx. Since the manoeuvre of depressing the tongue and visualizing the flap was stressful to the patient due to the presence of the wounds and mandibulotomy, this was done less frequently than the usual hourly observation. Postoperatively, tracheostomy could be removed and satisfactory oral swallowing could be initiated by six weeks. He was treated with adjuvant intensity modulated radiotherapy with $6 \mathrm{MV}$ photons with a dose of 60Gy in 30 fractions, which was tolerated well. After 18 months of follow-up he is symptomatically well, though imaging studies revealed residual disease.

\section{DISCUSSION}

Chordomas are comparatively slow growing malignant neoplasms derived from notochord. In the cranial region the tumours usually arise from the clivus. Clival chordomas usually present in the third and fourth decades of life and there is slight male preponderance. Surgical resection with or without adjuvant radiotherapy is the treatment of choice. Because of their locally invasive nature into the cervical spine, parasellar structures, and intradural extensions, true microscopic total removal of clival

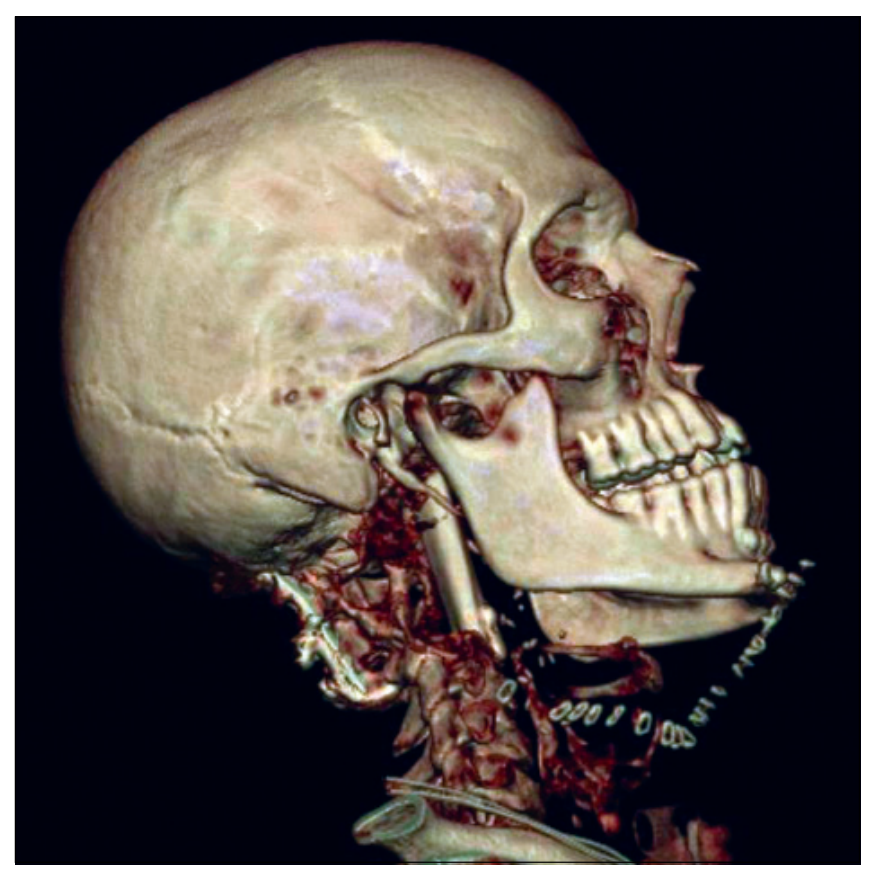

Figure 3: Postoperative three-dimensional CT image 
chordomas is typically not possible. ${ }^{[1]}$ The endoscopic trans-nasal trans-sphenoidal approach is described for smaller lesions. ${ }^{[2]}$ A maxillo-mandibular swing with a glossotomy has been suggested to be a better approach for larger lesions. ${ }^{[3]}$

Non vascularised bone grafts have been used successfully for the reconstruction of cervical spine. Iliac crest bones, autogenous and allogeneic segments of fibula have been reported. ${ }^{[4,5]}$ The success of these grafts relies on the healing capacity of the recipient bed. They heal by creeping substitution. This can take up to two years. ${ }^{[6,7]}$ Even with radiographic evidence of incorporation into the adjacent bone, distant portion of the graft may remain avascular and biomechanically weak. ${ }^{[8]}$

The advantage of vascularised bone is the superior healing in compromised settings. Pedicle flaps from the ribs have been used for thoracolumbar spinal reconstruction. ${ }^{[9,10]}$ Fibula provides straight tubular bone with excellent strength. ${ }^{[11,12]}$ Vascularised fibula transfer has been used to stabilize the cervical spine after tumour resection, ${ }^{[13]}$ severe kyphosis caused by degenerative arthritis, ${ }^{[14]}$ neurofibromatosis, ${ }^{[15]}$ chronic osteomyelitis ${ }^{[16]}$ and in a case of cervical spinal osteoradionecrosis and osteomyelitis following radiotherapy. ${ }^{[17]}$ In a recent paper, Winters et al. ${ }^{[18]}$ have described the use of free vascularised fibula in 21 patients for the reconstruction of spinal defects of which four cases were of cervical spine. Krishnan et al. ${ }^{[19]}$ have reported a case using free fibula for ventral spinal fusion at multiple levels. Other osteocutaneous donor sites such as iliac crest, scapula and radius have the disadvantages of excess soft tissue bulk and inadequate bone stock. Fibular skin paddle is thin and favours speedy resumption of swallowing.

Though there are a few earlier reports of this reconstructive technique, our case stands out as it demonstrates the complexity in the management of recurrent skull base chordomas, and the aptness of vascularised fibula osteocutaneous flap in the composite reconstruction of pharyngeal wall and cervical spine.

\section{REFERENCES}

1. Lanzino G, Dumont AS, Lopes MB, Laws ER Jr. Skull base chordomas: Overview of disease, management options, and outcome. Neurosurg Focus 2001;10:E12.

2. Frank G, Sciarretta V, Calbucci F, Farneti G, Mazzatenta
D, Pasquini E. The endoscopic transnasal transsphenoidal approach for the treatment of cranial base chordomas and chondrosarcomas. Neurosurgery 2006;59:ONS50-7

3. Hassan S, Abdullah JM, Wan Din SJ, Idris Z. Combined use of maxillomandibular swing approach and neurosurgical ultrasonic aspirator in the management of extensive clival chordoma: a case report. J Med Case Reports 2008;2:49

4. Bernard TN Jr, Whitecloud TS 3rd. Cervical spondylotic myelopathy and myeloradiculopathy: Anterior decompression and stabilization with autogenous fibula strut graft. Clin Orthop Relat Res 1987;221:149-60.

5. Macdonald RL, Fehlings MG, Tator $\mathrm{CH}$, Lozano A, Fleming JR, Gentili F, et al. Multilevel anterior cervical corpectomy and fibular allograft fusion for cervical myelopathy. J Neurosurg 1997;86:990-7.

6. Gross TP, Jinnah RH, Clarke HJ, Cox QG. The biology of bone grafting. Orthopedics 1991;14:563-8.

7. Burchardt $\mathrm{H}$. Biology of bone transplantation. Orthop Clin North Am 1987;18:187-96.

8. Rossier AB, Hussey RW, Kenzora JE. Anterior fibular interbody fusion in the treatment of cervical spinal cord injuries. Surg Neurol 1977;7:55-60.

9. Bradford DS. Anterior vascular pedicle bone grafting for the treatment of kyphosis. Spine (Phila Pa 1976) 1980;5:318-23.

10. Rose GK, Owen R, Sanderson JM. Transposition of rib with blood supply for the stabilisation of a spinal kyphos. J Bone Joint Surg (Br) 1975; 57:112.

11. Wittenberg RH, Moeller J, Shea M, White AA 3rd, Hayes WC. Compressive strength of autologous and allogenous bone grafts for thoracolumbar and cervical spine fusion. Spine (Phila Pa 1976) 1990;15:1073-8.

12. Smith MD, Cody DD. Load-bearing capacity of corticocancellous bone grafts in the spine. J Bone Joint Surg Am 1993;75:1206-13.

13. Wright NM, Kaufman BA, Haughey BH, Lauryssen C. Complex cervical spine neoplastic disease: Reconstruction after surgery by using a vascularised fibular strut graft. J Neurosurg 1999;90: 133-7.

14. Freidberg SR, Gumley GJ, Pfeifer BA, Hybels RL. Vascularised fibular graft to replace resected cervical vertebral bodies. Case report. J Neurosurg 1989;71:283-6.

15. Nemoto K, Asazuma T, Amako M, Kawaguchi M, Yamagishi M, Mizuno $\mathrm{H}$. Vascularised fibula graft for spinal fusion in severe cervical kyphosis due to neurofibromatosis. J Reconstr Microsurg 1997;13:559-62.

16. Erdmann D, Meade RA, Lins RE, McCann RL, Richardson WJ, Levin LS. Use of the microvascular free fibula transfer as a salvage reconstruction for failed anterior spine surgery due to chronic osteomyelitis. Plast Reconstr Surg 2006;117:2438-45

17. Ng RL, Beahm E, Clayman GL, Hassenbusch SJ, Miller MJ. Simultaneous reconstruction of the posterior pharyngeal wall and cervical spine with a free vascularised fibula osteocutaneous flap. Plast Reconstr Surg 2002;109:1361-5.

18. Winters $H A$, van Engeland $A E$, Jiya $T U$, van Royen BJ. The use of free vascularised bone grafts in spinal reconstruction. J Plast Reconstr Aesthet Surg doi:10.1016/j.bjps.2008.11.037

19. Krishnan KG, Müller $A$. Ventral cervical fusion at multiple levels using free vascularised double-islanded fibula - a technical report and review of the relevant literature. Eur Spine J 2002;11:176-82.

Source of Support: Nil, Conflict of Interest: None declared. 